\title{
Incidence of hypocalcemia and its changes of biochemical parameters in periparturient cows
}

\author{
Shi Shu, Cheng Xia**, Chuang Xu, Hongyyou Zhang, Ling Wu \\ College of Animal Science and Veterinary Medicine, Heilongjiang Bayi Agricultural University, Daqing, 163319, China
}

(Received: December 5, 2011; Revised: March 20, 2012; Accepted: March 23, 2012)

\begin{abstract}
In this study, we investigate the status of calcium (Ca) homeostasis at parturition in three dairy farms (I, II, and III), Heilongiiang, China. Twenty multiparous Holstein cows from each farm were randomly assigned to this experiment. The dietary cation-anion difference (DCAD) was $91 \mathrm{mEq} / \mathrm{kg}$ of DM for farm I, $152 \mathrm{mEq} / \mathrm{kg}$ of DM for farm II, and $85 \mathrm{mEq} / \mathrm{kg}$ of DM for farm III. Incidence of hypocalcemia was above $75 \%$ and urine $\mathrm{pH}$ was above 7.25 at calving in each farm. Compared to other farms, cows in farm II that fed the greatest positive DCAD had the lowest concentration of serum $\mathrm{Ca}$, the highest concentration of serum PTH, and the greatest urine $\mathrm{pH}$ at calving $(p<0.05)$. However, there was not significant difference in serum 1,25-dihydroxy-vitamin D and hydroxyproline concentration of the cows among three farms. This is the first study to confirm that hypocalcemia is very prevalent at calving in Chinese dairy farms, and the high positive DCAD is a major risk factor that results in hypocalcemia at calving, which may reduce ability of the cow to maintain Ca homeostasis.
\end{abstract}

Keywords : Ca homeostasis, cation-anion difference, dairy cows, hypocalcemia, urine $\mathrm{pH}$

Milk fever is a major metabolic disease that calcium (Ca) homeostatic mechanisms fail to maintain normal blood $\mathrm{Ca}$ levels around calving. Evaluation of $\mathrm{Ca}$ homeostatic mechanisms has increasingly contributed to the understanding of the fundamental mechanisms involved in milk fever [1]. However, there have been few reports about the Ca homeostatic capacity of dairy cows with hypocalcemia when calving in China. This study is a survey to status of hypocalcemia and levels of dietary cation anion difference (DCAD), urine $\mathrm{pH}$ and serum $\mathrm{Ca}$, hydroxyproline (HYP), alkaline phosphatase (ALP), parathyroid hormone (PTH), calcitonin (CT), 1,25-dihydroxy-vitamin D (DHVD) in three dairy farms, Heilongjiang province, China.

Tail venous blood and urine were collected using $10 \mathrm{~mL}$ tube and $50 \mathrm{~mL}$ cup respectively from twenty healthy cows within $12 \mathrm{~h}$ after calving in each dairy farm. The cows were Holstein breed with three to six years of age, fed the total mixed ration, and had the similar milk yield. The blood was centrifuged immediately after collection at $4,000 \mathrm{~g}$ for $10 \mathrm{~min}$ and serum was harvested. Serum $\mathrm{Ca}$ and HYP were determined using commercial kits (Chang Chun HuiLi Bioengineering, China). Serum concentration of PTH was measured at Nucleo-Radiology Department of Harbin Medical University in China using a commercially available radioimmunoassay kit (Beijing Atomic High Technology, China). Serum concentrations of DHVD were measured using a high performance liquid chromatography at Product Quality Monitoring Institute in Changchun, China. Serum Ca concentrations less than $2.20 \mathrm{mmol} / \mathrm{L}$ were considered to hypocalcemia [5]. Urine $\mathrm{pH}$ was detected using a precise $\mathrm{pH}$ test paper (Uritest 8A; Youlite Medical Electronic, China).

Feed from each dairy farm was collected at prepartum 10 days by quatation method. The DCAD was calculated using the formula DCAD $(\mathrm{mEq} / \mathrm{kg}$ of $\mathrm{DM})=[(\mathrm{Na} / 23+$ $\mathrm{K} / 39)-(\mathrm{Cl} / 35.5+\mathrm{S} / 16)]$ [3].

Student's $t$ test was used for comparison of means. The data were expressed as mean $\pm \mathrm{SD}$ and statistical significance was established at $p<0.05$.

In the three farms, survey showed incidence of hypocalcemia, DCAD and urine $\mathrm{pH}$ were above $75 \%$, $85 \mathrm{mEq} / \mathrm{kg}$ of DM and 7.25 at calving, respectively.

\footnotetext{
*Corresponding author

Tel: +86-0459-6819205, Fax: +86-0459-6819205

E-mail: xiacheng2011@gmail.com

Present address: College of Veterniary Medicine, Cornell University, Ithaca 14850, NY, USA.
} 
Table 1. Status of hypocalcemia and DCAD \& changes of seven parameters in dairy cows at $12 \mathrm{~h}$ after calving

\begin{tabular}{lccc}
\hline \multicolumn{1}{c}{ Parameter } & Farm I & Farm II & Farm III \\
\hline Ca $(\mathrm{mmol} / \mathrm{L})$ & $1.91(0.22)^{\mathrm{b}}$ & $1.82(0.23)^{\mathrm{a}}$ & $2.01(0.18)^{\mathrm{b}}$ \\
ALP $(\mathrm{U} / \mathrm{L})$ & $73(31)$ & $58(20)$ & $79(26)$ \\
HYP $(\mu \mathrm{g} / \mathrm{mL})$ & $2.63(0.21)$ & $2.31(0.23)$ & $2.52(0.24)$ \\
PTH $(p \mathrm{~mol} / \mathrm{L})$ & $192(35)^{\mathrm{b}}$ & $260(40)^{\mathrm{a}}$ & $220(33)^{\mathrm{b}}$ \\
CT $(p \mathrm{~mol} / \mathrm{L})$ & $36(10)$ & $39(8)$ & $34(9)$ \\
DHVD $(\mathrm{ng} / \mathrm{mL})$ & $26(8)$ & $27(7)$ & $25(6)$ \\
pH & $7.50(0.25)^{\mathrm{b}}$ & $8.00(0.25)^{\mathrm{a}}$ & $7.25(0.25)^{\mathrm{b}}$ \\
DCAD $(\mathrm{meq} / \mathrm{kg}$ of DM) & $91^{\mathrm{b}}$ & $152^{\mathrm{a}}$ & $85^{\mathrm{b}}$ \\
Incidence of hypocalcemia $(\%)$ & 80 & 80 & 75 \\
\hline
\end{tabular}

${ }^{\mathrm{a}, \mathrm{b}}$ Values superscripted by the different lower-case letters $(p<0.05)$ between three farms. ALP: alkaline phosphatase, Ca: calcium, CT: calcitonin, DCAD: dietary cation-anion difference, DHVD: 1,25-dihydroxyvitamin D, HYP: hydroxyproline, PTH: parathormone.

Dairy cows in farm II had the highest DCAD $(p<0.05)$, urine $\mathrm{pH}$ and serum PTH concentration $(p<0.05)$, still had the lowest serum Ca concentration $(p<0.05)$. Level of serum CT, DHVD, ALP, and HYP was not significantly different among three farms (Table 1).

Some studies suggested that DCAD before calving should be under $40 \mathrm{mEq} / \mathrm{kg}$ of DM to reduce incidence of hypocalcemia (less than 50\%), maintain normal urine $\mathrm{pH}(6.5 \sim 7.0)$ and blood $\mathrm{Ca}$ (more than $2.20 \mathrm{mmol} / \mathrm{L}$ ) [2, 4]. The high positive DCAD before parturition, resulted from high content of dietary $\mathrm{K}$ or $\mathrm{Na}$, is an important etiologic factor of milk fever $[1,5]$. The high dietary $\mathrm{Na}$ or $\mathrm{K}$ result in a state of metabolic alkalosis, which reduces the responsiveness of bone and kidney to $\mathrm{PTH}$ $[2,6]$. It has been known that PTH is the major factor that controls bone osteoclast activity. When cows have a negative $\mathrm{Ca}$ balance which stimulates secretion of $\mathrm{PTH}$, the secreted PTH enhances bone Ca resorption, and activates renal tubules to produce DHVD during transition period resulting in elevated serum $\mathrm{Ca}$, HYP and ALP usually ought to increase [3, 7]. In the present study, cows have a lower concentration of serum $\mathrm{Ca}$ and increased secretion of PTH, especially in farm II, which suggests that response of PTH to low $\mathrm{Ca}$ is active to prevent a severe decline of serum $\mathrm{Ca}$. However, there is no difference in serum ALP, HYP, and DHVD among three farms, which implies that the bones and kidney of the cows fed the high positive DCAD may be refractory to PTH stimulation. Thus, further research is needed to elucidate the detailed reason for so high incidence of hypocalcemia.

In conclusion, the high incidence of hypocalcemia was a serious problem in three farms, which may be associated with high positive DCAD. The high DCAD is a major risk factor for hypocalcemia before calving that may induce metabolic alkalosis and then reduce the ability of the cow to maintain $\mathrm{Ca}$ homeostasis.

\section{Acknowledgments}

This study was funded by the China National Science Foundation Committee (30972235), Heilongjiang Province Science Foundation (C200916) and Agricultural Reclamation Head Office of Heilongjiang Province (HNKXIV-08-01-07).

\section{References}

1. Goff JP. Major advances in our understanding of nutritional influences on bovine health. J Dairy Sci 2006, 89, 1292-1301.

2. Goff JP. The monitoring, prevention, and treatment of milk fever and subclinical hypocalcemia in dairy cows. Vet J 2008, 176, 50-57.

3. Heron VS, Tremblay GF, Oba M. Timothy hays differing in dietary cation-anion difference affect the capability of dairy cows to maintain their calcium homeostasis. J Dairy Sci 2009, 92, 238-246.

4. Horst RL, Goff JP, Reinhardt TA, Buxton DR. Strategies for preventing milk fever in dairy cattle. J Dairy Sci 1997, 80, 1269-1280.

5. Larsen T, Moller G, Bellio R. Evaluation of clinical and clinical chemical parameters in periparturient cows. J Dairy Sci 2001, 84, 1749-1758.

6. Lean IJ, DeGaris PJ, McNeil DM, Block E. 
Hypocalcemia in dairy cows: meta-analysis and dietary cation anion difference theory revisited. J Dairy Sci 2006, 89, 669-684.

7. Liesegang A, Eicher R, Sassi ML, Risteli J, Kraenzlin M, Riond JL, Wanner M. Biochemical markers of bone formation and resorption around parturition and during lactation in dairy cows with high and low standard milk yields. J Dairy Sci 2000, 83, 1773-1781. 